\title{
A Historic Revision and Bibliometric Analysis of Heat Transfer Simulation Research from 2007 to 2017
}

\author{
Guillermo Eliecer Valencia Ochoa*, David Andrés Lorduy Martínez, Erni Stiwar Ramos Banda \\ Grupo de investigación en Gestión Eficiente de la Energía - Kaí, Faculty of Engineering \\ Universidad Del Atlántico, km 7 antigua vía Puerto, 081008, Barranquilla, Colombia. \\ *guillermoevalencia@mail.uniatlantico.edu.co
}

\begin{abstract}
A bibliometric analysis of published researches about heat transfer simulation (HTS) for a period of time since 2007 until 2017 is conducted based on Web of Science Core Collection. The quest identified a total of 1169 publications related with HTS in the period. The patterns of the publication results, subject categories, relevant journals, international productivity and collaboration, geographic distribution of authors, and keywords of authors were analysed. The anual number of publications in the quest increased from 68 in 2007 to 138 in 2017, highlighting 2016 as the year with the highest increase rate with 167 pulications. "Chemical Engineering, Fluid Flow and Transfer Processes", "Energy \& Energy Engineering and Power Technology", and "Engineering \& Engineering" were the three main categories of the most relevant topics. International Journal of Heat and mass Transfer, is considered the main journal of the topicwith the greatest number of publications. China, Iran and the USA were the three most productive countries. The most productive institution was Xi An Jiao Tong Univ, followed by the Indian Inst Technol and Islamic Azad Univ. Iran was the most frequent partner in international collaborations. Thisstudy revealed subyacent patterns in results and academic collaborations which can be useful as an alternative way to reveal tendencies of heat transfer simulation.
\end{abstract}

Keywords-Bibliometric, Simulation, Heat transfer,Scientific products

\section{INTRODUCTION}

The heat transfer simulation is based on computational studies and simulation tools of heat transfer phenomenon, which is present in a great percentage of preservation processes. In recent researches, the separation of variables, or also called analytic method, is being used to model and simulate heat transfer processes in order to calculate thermal properties, such as thermal conductivity $\left(\mathrm{W} / \mathrm{m}^{\circ} \mathrm{C}\right)$ and thermal diffusivity $\left(\mathrm{m}^{2} / \mathrm{s}\right)$, as well as properties of the energy transfer environment, such as the heat transfer coefficient $\left(\mathrm{W} / \mathrm{m}^{\circ} \mathrm{C}\right)$. An alternative in the simulation is to develop the equations, using a proper quantity of terms to improve the temperature profiles studied. The simulation of heat transfer is widely applied to food preservation in simulation models of drying processes which are far from being considered simple processes [1], this process has significant variables such as the air temperaturr, air speed, the thickness of the material, previous surface treatments applied to the material, and so forth and so on [2]. Similarly, the currently drying models proposed are difficult to develop, generally the transport properties are difficult, even more, to obtain their derivative [3], which can be observed in other investigations around this simulation processes [4], [5], [6], [7]. So that can be possible to simulate the heat transfer processes involved in drying, it is necessary to characterize the physiscarl properties and how they affect to the processs. It is possible to obtain a more precise procedure when multiphysic approximations are applied [8], [9], [10], [11].

At the moment to have a general overview about heat transfer simulation, it is possible to find researches about the thermal conductivity behaviour in nanofluids, which is expected to increase the heat transfer rate in comparison to the thermal conductivity in conventional fluids [12]. [13], [14] The first term to use is nanofluids to refer to the fluids with suspended nanoparticles. In conventional heat transfer, several investigations [15], [16], [17], [18] state that the use of low concentrations of nanoparticles can increase the conductivity .

A grat number of authors have published researches about heat transfer simulation processes in different journals around the world. However, there have been few tries to recopilate systematic data about the world scientific production of the investigation with SHT. A common research tool is the bibliometric analysis method that has already been applied in the scientific production and different studies of trending topics in a lot of disciplines of Science and Engineering ([19], [20], [21]). The conventional bibliometric methods are focused in the analysis of cites and content, while the recent bibliometric analysis focus on the academic results of authors, institutions and countries, identifies the temporary evolution of the research patterns and sustains the international collaboration. 
In this article, a bibliometric analysis was conducted about the investigations in heat transfer simulation published since 2007 until 2017. The objective of this study was to reveal the subjacent patterns in the scientific results, the characteristics of the international collaboration and the distribution of authors in with respect to the topics, and finally to provide a potential guide for future investigations related with heat transfer simulation.

\section{DATA SOURCES AND METHODOLOGY}

The selecteddata was based on the online versions of (ISI) Citation Indexes, a source that can be accessed through Web of Science. Which contains information about multidisciplinary research of high quality publication in the most relevant journals. This source identifies and indexes the most important publications in every area of sciences with every significant documents contained in such publications. Web of Science is a bibliographic database which records contain information such as titles, authors, keywords, summaries, cited references, and so on. The investigation based over the obtained data from Web of Science was focused ona main topic, which is heat transfer simulation, and similar topics, in order to compilate a bibliography fromall the related documents with the investigation. Through all the documents complied, there were eliminated those publications in which heat transfer simulation wasnot used as main theme or subtheme were eliminated from the data set. Subsequently, the information collected was classified in individual groups, including author(s), category(ies), subject(s), journal(s), title(s), year(s) of publication, so that can be possible to avoid the duplicated registers of publications.

All the publications identified in the databases related with heat transfer simulation were evaluated through the following criteria: results and publications; subject categories,journals, international productivity and collaboration; geographic distribution of the authors; and keywords using Microsoft Excel 2013®. The impact factor (IF) of each journalwas obtained from Web of Science in the year of 2016. The type of collaboration was determined by the addresses of the authors, where the term "Unique country publications" was assigned if the addresses from the researchers were from the same country. The term "publication of an unique institute" was assigned if the addresses of the researchers belonged to the same institution.

\section{A. Results of publications}

From 2007 to 2017, a total of 1169 publication related with heat transfer simulation (SHT) were identified. The annual number of publications of SHT increased from 68 in 2007 to 138 in 2017. The accumulated progression was presented by an exponential model (Fig. 1). This adjustment produced a high correlation coefficient of the compiled data $(R 2=0,8953)$. It was concluded that the number of scientific articles about heat transfer simulations, did grow at a slow rate. The most suitable exponential adjustment for the SHT research was $=6 E-73 e 0,085 x$, where " $\mathrm{y}$ " is the accumulated number of publications and " $\mathrm{x}$ " is the number of years since 2007, extrapolating from the exponential. Nine types of documents were found in all the publications related with the SHT researches during a period time of 10 years.

Articles was the most frequently used type of document with $91,7 \%$ of the total production, followed by procedure documents with $6,2 \%$, reviews with $1,3 \%$, editing house materials with $0,3 \%$, corrections $0,2 \%$, letters, summaries, recentarticles and reprint (0,1\%). 98,8\% of all articles were published in English (1155), followed by Chinese (7), German (2), Japanese (2), Polish, Portuguese and Spanish (1). Withinthe group of study, $7,2 \%$ of references were cited by article in 2007 , compared with $15,5 \%$ in $2009,7,6 \%$ in $2011,11,8 \%$ in $2013,4,8 \%$ in 2015 and $0,5 \%$ in 2017 . It can be observed the remarkable decreasing percentage in referencearticles of heat transfer simulation.

\section{B. Categories and relevant journals}

There is a wide variety with respect to the research topic of heat transfer simulation, including a great number of categories and topicsidentified in the last 20 years. The distribution of the 10 main categories of themes are shown in the Table I, which highlights the categories "Chemical Engineering \& Fluid Flow and Transfer Processes" (202, 17.29\%), "Energy \& Energy Engineering and Power Technology" (66, 5.64\%), y "Engineering \& Engineering (miscellaneous)" (64, 5.47\%)as the 3 most popular categories. Due to the fact that the use of statistics in each discipline would be considered a key element to evaluate its grade of maturity[22], [23], [24]. The results provide a current vision of the emphasis of the investigation in this topic. 


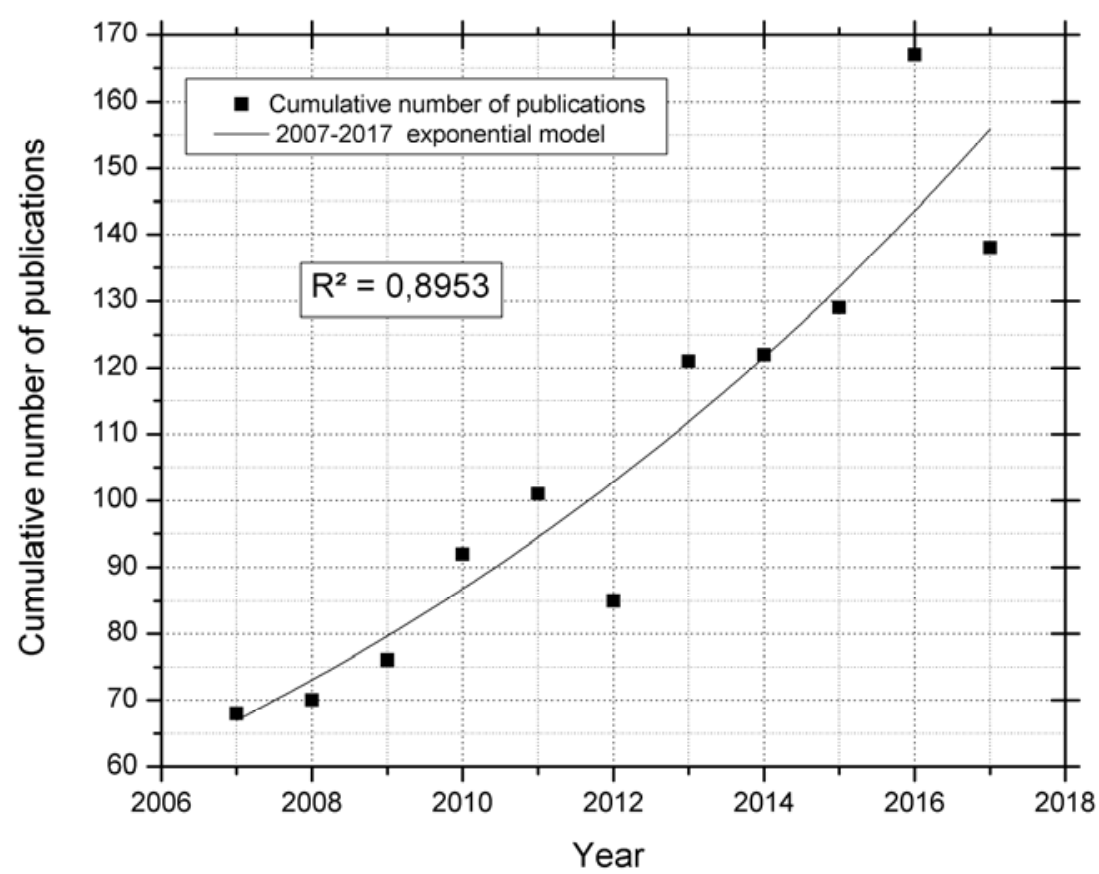

Fig.1. Exponential model of the accumulative of publications from 2007 to 2017

TABLE I. Top 10 Distribution of Thematic Categories

\begin{tabular}{|c|c|l|}
\hline Theme and Category & TP* & \multicolumn{1}{|c|}{ TP (\%) } \\
\hline Chemical Engineering \& Fluid Flow and Transfer Processes & 202 & $1(17.29)$ \\
\hline Energy \& Energy Engineering and Power Technology & 66 & $2(5.64)$ \\
\hline Engineering \& Engineering (miscellaneous) & 64 & $3(5.47)$ \\
\hline Chemical Engineering \& Chemical Engineering (miscellaneous) & 46 & $4(3.93)$ \\
\hline Mathematics \& Numerical Analysis & 32 & $5(2.73)$ \\
\hline Energy \& Nuclear Energy and Engineering & 27 & $6(2.3)$ \\
\hline Engineering \& Mechanical Engineering & 23 & $7(1.96)$ \\
\hline Computer Science \& Computer Science Applications & 15 & $8(1.28)$ \\
\hline Engineering \& Building and Construction & 8 & $9(0.68)$ \\
\hline Energy \& Energy Engineering and Power Technology & 8 & $10(0.68)$ \\
\hline
\end{tabular}

$\mathrm{TP}$ is the publications total, $\mathrm{R}$ is the rank, \% is the share in the publication

Table IIdisplaysthe distribution of the results in a top 10 of relevant journals, which places International Journal of Heat and mass transfer as the most relevant journal in with respect to the topic by itsof publications, followed by Applied Thermal Engineering and Numerical Heat transfer Part a-Applications. The impact factor (IF) generally is used to evaluate the relative importance of a journal, specially between others in the same field [25], [26], [27]. Nonetheless, when the impact factor is used as an indicator of the quality of the article, the IF of the journalmight cause an overestimationin the least important articles at a expense of the articles with higher impact ([28]). due to the impact factor of a journalmayvary between different fields, the average citation score(TC/TP) in the SHT investigation, that only considers the citeswithina determined field, is a more relevant measure of the relative importance of a journalin a specific field. 
TABLE II. Top 10 in Magazine Distribution

\begin{tabular}{|c|c|l|c|c|c|}
\hline Magazines & TP & TP R (\%) & TC & TC/TP & IF \\
\hline International Journal of Heat and mass Transfer & 124 & $1(10.6)$ & 1896 & 15,2903 & 3.458 \\
\hline Applied Thermal Engineering & 66 & $2(5.6)$ & 649 & 9,83 & 3.444 \\
\hline Numerical Heat Transfer Part a-Applications & 32 & $3(2.7)$ & 309 & 9,65 & 2.259 \\
\hline Heat and mass Transfer & 31 & $4(2.7)$ & 180 & 5,80 & 1.233 \\
\hline $\begin{array}{c}\text { International Communications in heat and mass } \\
\text { Transfer }\end{array}$ & 31 & $5(2.7)$ & 633 & 20,41 & 3.718 \\
\hline International Journal of Thermal Sciences & 30 & $6(2.6)$ & 339 & 11,3 & 3.615 \\
\hline Journal of heat Transfer-Transactions of the asme & 25 & $7(2.1)$ & 212 & 8,48 & 1.866 \\
\hline International Journal of heat and Fluid flow & 21 & $8(1.8)$ & 440 & 20,95 & 1.873 \\
\hline Nuclear Engineering and Design & 19 & $9(1.6)$ & 153 & 8,05 & 1.142 \\
& & & & & 0.868 \\
\hline Heat Transfer Research & 17 & $10(1.5)$ & 54 & 3,17 & 0.868 \\
\hline
\end{tabular}

TP is the publications total, TC is the quote total, IF is the impact factor, $\mathrm{R}$ is the rank, \% is the publication share

The 21 publications related with heat transfer simulation, published in Web of Science Core Collection presentedan average citation scoreof 20,95 and an IF of (1.873) in 2016 classified in first place, whilethe second place was forInternational Communications in Heat and mass Transfer with highest IF (3.718) in 2016 and an average citation score of 20,4 between the 10 numbered magazines in the TableII.

\section{International productivity and collaboration}

The contribution of different countries/territories was estimated by the locationof affiliated institutions of at least one author. The 10 main countries/territories were classified according to the total number of publications, including the publications of a single country/territory and the international collaborations. As it's shown in the TableII, China Republic led the productivity ranking with 322 publications, which is qualified with an H-índex (LCS) of 4 and an H-índex (GCS) of 23. Iran published the second highest number of total publications, followed by USA, Germany and France. The ratio of publications in a single country was evaluated, resulting in China with the highest ratio of (27,5\%). From these 10 countries/territories, 4 were from Europe, 4 from Asia, 2 from North America. The most of these 10 countries/territories were developed countries/territories. The network of collaboration of the 20 most productive countries was visualized using Ucinet (Fig. 2). Every point represents a country/territory and the width of the lines of interconnected lines represents the strength of the collaboration. As it can be seen, the collaborations between the 20 main most productive countries, were frequent. United States, France and England occupy the first place in collaboration from the most productive countries. The study of international productivity and collaboration, is a research topic that is frequently used which generates researches around this theme [29], [30], [31].

The H-índex proposed by [32], is a system that have induced a great impact in the quantification of productivity of the researchers and their investigations, which has influenced a great quantity of researches about this topic[33], [34], [35]. There has been created favorable modifications to this system in different ways: a global index that improves the form of evaluation [36], electronic index [37], a contemporary index [38], index of ordered cites by age, which indicates the best way of evaluation [39], an individual index [40]. The objective of this part is to demonstrate the contribution of the different institutions, therefor was estimated by the affiliated institution of at least one author. As it has been displayedin the TableIV, the most productive institution was Xi An Jiao Tong Univ with 33 articles, followed up by Indian Inst Technol with 24, the Islamic Azad Univ with 22, the BabolUnivTechnol con 21, the Chinese Acad Sci. The academy of sciences of China published the majority of publications of institutions, followed up by the Iran science academy; the university of BabolTechnol, who occupies the first place in H-índex of local collaboration and also the first place in H-índex in international collaboration, followed up by the Xi An Jiao Tong Univ which occupies the second place in $\mathrm{H}$ índex in international collaboration. 
TABLE III. The 10 Most Productive Countries / Territories During 2007-2017

\begin{tabular}{|c|c|c|c|c|}
\hline Countries/Territories & TP & TP R (\%) & H-índex (LCS) & H-índex (GCS) \\
\hline China & 322 & $1 \quad(27.5)$ & 4 & 23 \\
\hline Irán & 136 & 2 (11.6) & 4 & 22 \\
\hline USA & 133 & $3 \quad(11.4)$ & 4 & 21 \\
\hline Alemania & 71 & $4 \quad(6.1)$ & 2 & 14 \\
\hline Francia & 55 & $5 \quad(4.7)$ & 4 & 15 \\
\hline UK & 54 & $6 \quad(4.6)$ & 3 & 11 \\
\hline India & 53 & $\begin{array}{ll}7 & (4.5)\end{array}$ & 2 & 13 \\
\hline Canadá & 41 & $8 \quad(3.5)$ & 2 & 15 \\
\hline Rusia & 39 & $\begin{array}{ll}9 & (3.3)\end{array}$ & 1 & 6 \\
\hline Japón & 38 & $10(3.3)$ & 1 & 9 \\
\hline
\end{tabular}

TP is the publications total, H-índex (LCS) is the local quoting score, H-índex (LGS) is the global quoting score, $\mathrm{R}$ is the rank, $\%$ is the share in the publication

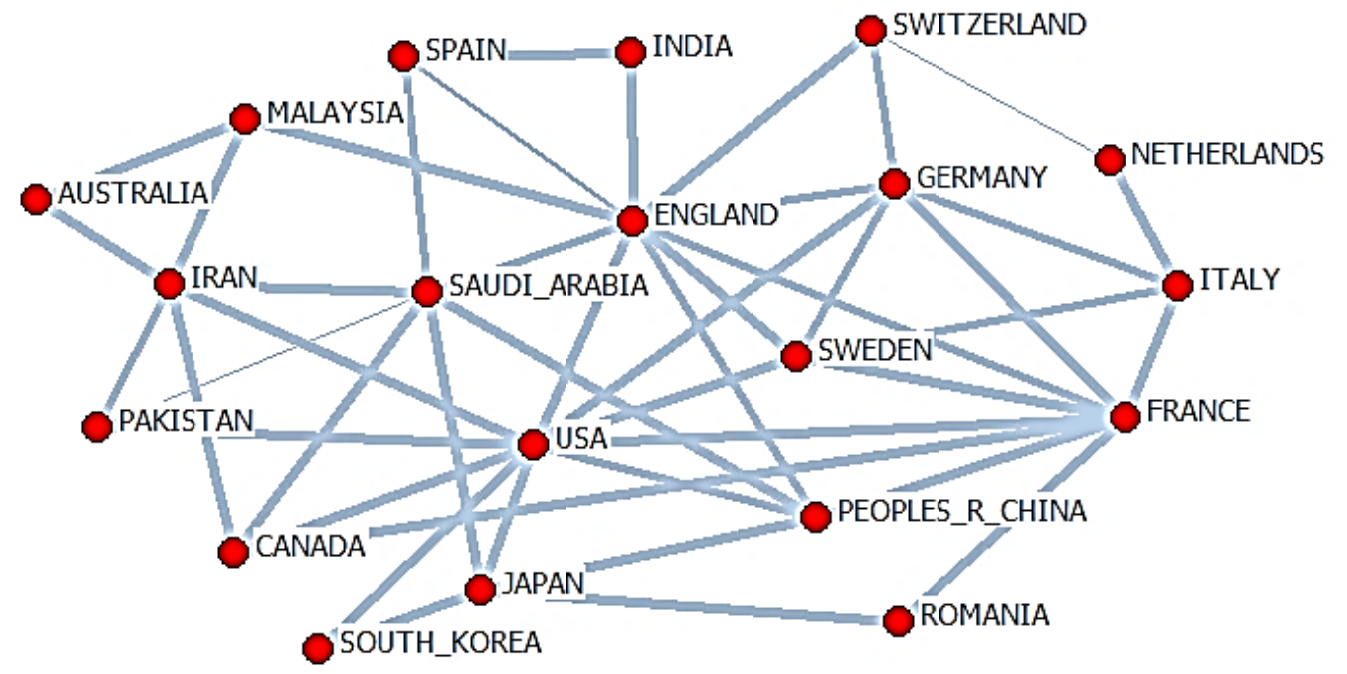

Fig.2. Collaboration network of the top 20 most productive countries/territories

Germany, France, the UK, Canada, USA, Russia and Japan are found in the 10 most productive countries/territories, none of these countries institutions figured up among the top 10 of most productive institutions, therefore, 5 were from China, 3 from Iran, 1 from India and Netherlands. Although Netherlands was not included in the 10 most productive countries/territories, the total publicationof the Academy of Netherlands occupied the ninth place. The Fig. 3 represents the network of collaboration of the most productive institutions. Every point represents an institution and the width of the interconnection lines represent the strength.

TABLE IV. The 10 Most Productive Institutions During 2007-2017

\begin{tabular}{|c|c|c|c|c|}
\hline Institutions & TP & TP R (\%) & H-índex (LCS) & H-índex (LGS) \\
\hline Xi An Jiao Tong Univ, China & 33 & $1(2.8)$ & 1 & 10 \\
\hline Indian Inst Technol, India & 24 & $2(2.1)$ & 2 & 8 \\
\hline Islamic Azad Univ, Irán & 22 & $3 \quad(1.9)$ & 1 & 8 \\
\hline BabolUnivTechnol, Irán & 21 & $4(1.8)$ & 4 & 12 \\
\hline Chinese AcadSci, China & 19 & $5(1.6)$ & 1 & 5 \\
\hline Tsinghua Univ, China & 19 & $6 \quad(1.6)$ & 1 & 4 \\
\hline Zhejiang Univ, China & 19 & $7 \quad(1.6)$ & 3 & 8 \\
\hline Harbin Inst Technol, China & 18 & $8 \quad(1.5)$ & 1 & 5 \\
\hline Eindhoven Univ Technol, Países bajos & 16 & $9 \quad(1.4)$ & 3 & 9 \\
\hline Isfahan UnivTechnol, Irán & 16 & $10(1.4)$ & 2 & 6 \\
\hline
\end{tabular}

TP is the publications total, H-índex (LCS) is the local quoting score, H-índex (LGS) is the global quoting score, $\mathrm{R}$ is the rank, \% is the share in the publication. 


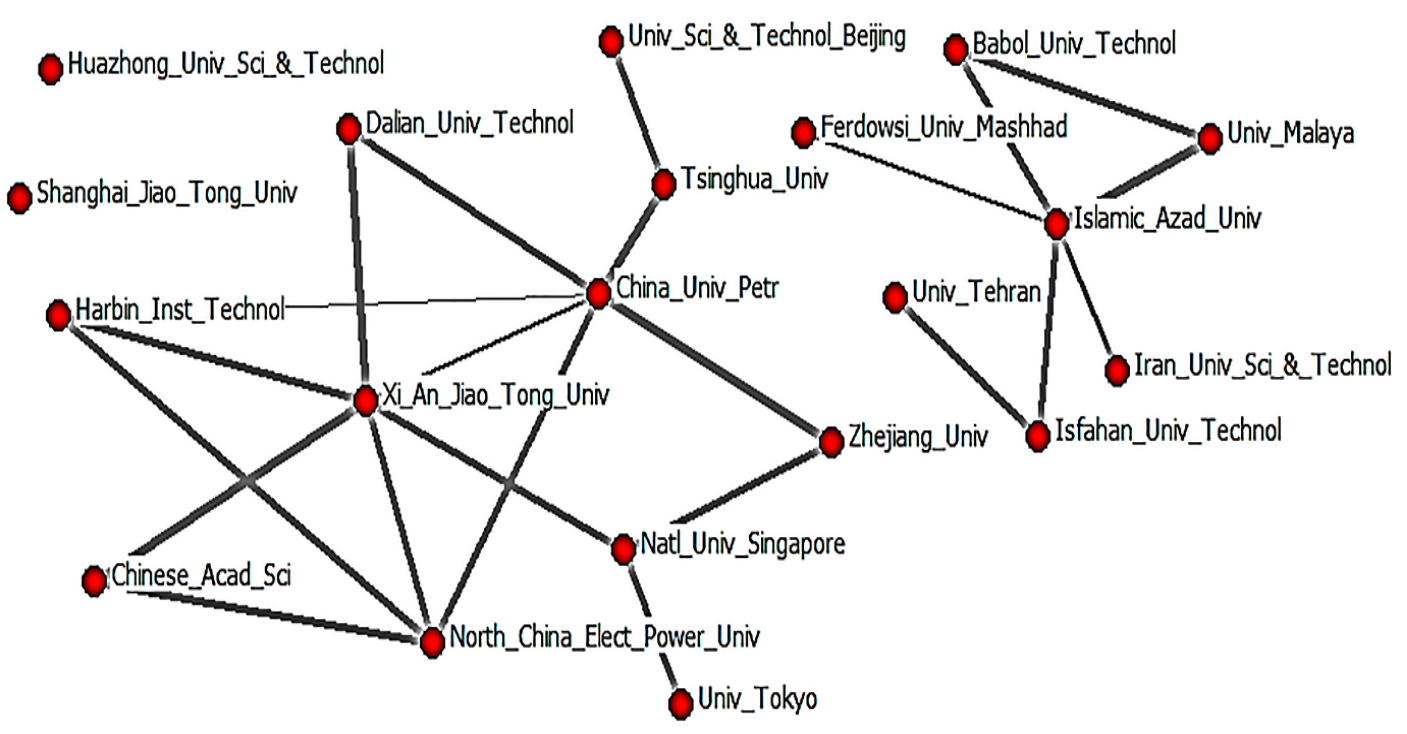

Fig.3. Collaboration network of the top 20 most productive institutions

Through an analysisof the data obtained from the Fig. 4, it can be observed that the 20 most collaborative institutions. It was found that the institutions in the same country tended to have a greater rate of collaboration than with institution in other countries, Xi An Jiao Tong Univ and the Chinese AcadSci, the Islamic Azad Univ and BabolUnivTechnol, Isfahan UnivTechnol and the Islamic Azad Univ, Tsinghua Univ and Zhejiang Univ.

\section{Author keywords}

The analysis of the author keywords offers a vision of the research trends, revealing areas of interest of the researcher. TableV, allows to observe the main keywords that appeared in published articles from 2007 to 2017 which are quantifiedand classified. In the setof data, there was used a total of 2201 keywords, from which it was realized a top 20 of the most used words by authors in the TableV. It indicates that "Heat" $(1164,99.6 \%)$, "Transfer" (1161, 99.3\%), "Simulation" (992, 84.9\%) were the 3 most popular ones. This abundance of single use keywords suggests a lack of continuity in the research and a great disparity in the research focuses.

During the period time studied, some keywords have been mantained notably in activity. For instance, the ranking of " Heat " passed from the 1st in 2007-2009 and returned in 2015-2017; " Transfer "passed from 2nd in 2007-2009 at 1st in 2010-2014, having a return to their initial place in the period of 2015-2017; finally "Using"passed from the 16th place in 2007-2009 to 10th in 2015-2017, this last one showing possible changes in the focus towards new areas of research with heat transfer simulation.

TABLE V. Top 20 Author Keywords

\begin{tabular}{|c|c|c|c|c|c|c|c|c|}
\hline Author Keywords & TP & TP R (\%) & \multicolumn{2}{|c|}{$\mathbf{2 0 0 7 - 2 0 0 9}$} & \multicolumn{2}{|c|}{$\mathbf{2 0 1 0 - 2 0 1 4}$} & \multicolumn{2}{|c|}{$\mathbf{2 0 1 5 - 2 0 1 7}$} \\
\hline & & & $\mathbf{P}$ & $\mathbf{R}$ & $\mathbf{P}$ & $\mathbf{R}$ & $\mathbf{P}$ & $\mathbf{R}$ \\
\hline Heat & 1164 & $1(99.6)$ & 213 & 1 & 518 & 2 & 433 & 1 \\
\hline Transfer & 1161 & $2(99.3)$ & 211 & 2 & 519 & 1 & 431 & 2 \\
\hline Simulation & 992 & $3(84.9)$ & 189 & 3 & 435 & 3 & 368 & 3 \\
\hline Numerical & 466 & $4(39.9)$ & 82 & 4 & 205 & 4 & 179 & 4 \\
\hline Flow & 319 & $5(27.3)$ & 67 & 5 & 144 & 5 & 108 & 5 \\
\hline Simulations & 178 & $6(15.2)$ & 26 & 8 & 86 & 6 & 66 & 6 \\
\hline Fluid & 155 & $7(13.3)$ & 21 & 10 & 78 & 7 & 56 & 7 \\
\hline Mass & 132 & $8(11.3)$ & 33 & 7 & 57 & 8 & 42 & 8 \\
\hline Using & 91 & $9(7.8)$ & 9 & 16 & 44 & 9 & 38 & 10 \\
\hline Convection & 84 & $10(7.2)$ & 15 & 13 & 35 & 11 & 34 & 11 \\
\hline Turbulent - & 84 & $11(7.2)$ & 25 & 9 & 36 & 10 & 23 & 16 \\
\hline Lattice & 78 & $12(6.7)$ & 6 & 17 & 30 & 13 & 42 & 8 \\
\hline Boltzmann & 74 & $13(6.3)$ & 6 & 17 & 29 & 14 & 39 & 9 \\
\hline Convective & 72 & $14(6.2)$ & 12 & 14 & 32 & 12 & 28 & 14 \\
\hline Method & 72 & $15(6.2)$ & 10 & 15 & 29 & 14 & 33 & 12 \\
\hline
\end{tabular}




\begin{tabular}{|c|c|c|c|c|c|c|c|c|}
\hline Large - & 69 & $16(5.9)$ & 19 & 11 & 30 & 13 & 20 & 17 \\
\hline Eddy - & 65 & $17(5.6)$ & 17 & 12 & 30 & 13 & 18 & 18 \\
\hline Cfd & 64 & $18(5.5)$ & 12 & 14 & 28 & 15 & 24 & 15 \\
\hline Model & 64 & $19(5.5)$ & 12 & 14 & 19 & 17 & 33 & 12 \\
\hline Phase & 64 & $20(5.5)$ & 9 & 16 & 24 & 16 & 31 & 13 \\
\hline
\end{tabular}

$\mathrm{TP}$ is the publication total, $\mathrm{P}$ are the publications in the study period, $\mathrm{R}$ is the occupied position in the study range, $\%$ is the share in the publication

It is surprising to find from 2007 to 2017 , topicsthat previously were very popular and have diminished in importance. For example, "Turbulent", "Large" y "Eddy" we classified in tenth, eleventh and twelfth respectively in 2007-2009, but they decreased to 16th, 17th y 18th respectively in 2015-2017.

\section{IV.CONCLUSION}

A bibliometric analysis of the patterns of publications, categories, topicsand journals, productivity and international collaboration, geographical distribution of authors, and author keywords in documents related to heat transfer simulation in the period from 2007 to 2017 was conducted in this paper. The research highlighted important tendencies in the world, areasof the investigation during the whole period. a total 1169 publications were made during the period 2007-2017. The publications are added year by year, the annual growing rate of publications in the SHT research is in constantincreasing "Chemical Engineering \& Fluid Flow and Transfer Processes", "Energy \& Energy Engineering and Power Technology", and "Engineering \& Engineering (miscellaneous)" were the 3 journalswith more publications about SHT. And the 3 most popular categories.

United States and China were the most frequent international partners. The most productive institution was the Xi An Jiao Tong Univ, followed up by the Academy of Sciences of India (Indian Inst Technol) and the Islamic Azad Univ. The author keywords offer a vision of the research trends, revealing that areas of research. "Heat", "Transfer" y "Simulation" are growing topicsof research in the field of heat transfer simulation, while "Turbulent", "Large" y "Eddy" are gradually less significant.

\section{REFERENCES}

[1] J. Y. Liu and W. T. Simpson, "Solutions of diffusion equation with constant diffusion and surface emission coefficients," Dry. Technol., vol. 15, no. 10, pp. 2459-2477, 1997.

[2] S. Erenturk and K. Erenturk, "Comparison of genetic algorithm and neural network approaches for the drying process of carrot," J. Food Eng., vol. 78, no. 3, pp. 905-912, 2007.

[3] E. Roca, V. Guillard, B. Broyart, S. Guilbert, and N. Gontard, "Effective moisture diffusivity modelling versus food structure and hygroscopicity," Food Chem., vol. 106, no. 4 SPEC. ISS., pp. 1428-1437, 2008.

[4] R. K. Goyal, A. R. P. Kingsly, M. R. Manikantan, and S. M. Ilyas, "Mathematical modelling of thin layer drying kinetics of plum in a tunnel dryer," J. Food Eng., vol. 79, no. 1, pp. 176-180, 2007.

[5] H. Pahlavanzadeh, A. Basiri, and M. Zarrabi, "Determination of Parameters and Pretreatment Solution for Grape Drying," Dry. Technol., vol. 19, no. 1, pp. 217-226, 2001.

[6] E. Akpinar, A. Midilli, and Y. Bicer, "Single layer drying behaviour of potato slices in a convective cyclone dryer and mathematical modeling," Energy Convers. Manag., vol. 44, no. 10, pp. 1689-1705, 2003.

[7] E. Mirzaee, S. Rafiee, A. Keyhani, and Z. Emam-Djomeh, "Determining of moisture diffusivity and activation energy in drying of apricots,” Res. Agric. Eng., vol. 55, no. 3, pp. 114-120, 2009.

[8] T. Jokiniemi, K. Kautto, E. Kokin, and J. Ahokas, "Energy efficiency measurements in grain drying," Agron. Res., vol. 9, no. SPPL. ISS. 1, pp. 69-75, 2011.

[9] P. S. S. Mirade and J. D. D. DAUDIN, “A numerical study of the airflow patterns in a sausage dryer," Dry. Technol., vol. 18, no. 1-2, pp. 81-97, 2000.

[10] P. S. Mirade, "Prediction of the air velocity field in modern meat dryers using unsteady computational fluid dynamics (CFD) models," J. Food Eng., vol. 60, no. 1, pp. 41-48, 2003.

[11] J. F. Le Page, C. Chevarin, A. Kondjoyan, J. D. Daudin, and P. S. Mirade, "Development of an approximate empirical-CFD model estimating coupled heat and water transfers of stacked food products placed in airflow," J. Food Eng., vol. 92, no. 2, pp. 208-216, 2009.

[12] S. Kakaç and A. Pramuanjaroenkij, "Review of convective heat transfer enhancement with nanofluids," Int. J. Heat Mass Transf., vol. 52, no. 13-14, pp. 3187-3196, 2009.

[13] S. U. S. Choi and J. A. Eastman, "Enhancing thermal conductivity of fluids with nanoparticles," ASME Int. Mech. Eng. Congr. Expo., vol. 66, no. March, pp. 99-105, 1995.

[14] S. U. S. Choi, Z. G. Zhang, W. Yu, F. E. Lockwood, and E. A. Grulke, "Anomalous thermal conductivity enhancement in nanotube suspensions," Appl. Phys. Lett., vol. 79, no. 14, pp. 2252-2254, 2001.

[15] H. Masuda, A. Ebata, K. Teramae, and N. Hishinuma, "Alteration of Thermal Conductivity and Viscosity of Liquid by Dispersing Ultra-Fine Particles. Dispersion of Al2O3, SiO2 and TiO2 Ultra-Fine Particles.,” Netsu Bussei, vol. 7, no. 4, pp. 227-233, 1993.

[16] S. Lee, S. U.-S. Choi, S. Li, and J. A. Eastman, "Measuring Thermal Conductivity of Fluids Containing Oxide Nanoparticles," J. Heat Transfer, vol. 121, no. 2, p. 280, 1999.

[17] Y. Xuan and Q. Li, "Heat transfer enhancement of nanofluids," Int. J. heat fluid flow, vol. 21, no. 1, pp. 58-64, 2000.

[18] Y. Xuan and W. Roetzel, "Conceptions for heat transfer correlation of nanofluids," Int. J. Heat Mass Transf., vol. 43, no. 19, pp. 3701$3707,2000$.

[19] T. C. Almind and P. Ingwersen, "Informetric analyses on the world wide web: methodological approaches to "webometrics,"” J. Doc., vol. 53 , no. 4, pp. 404-426, 1997 .

[20] B. Cronin, "Bibliometrics and beyond: some thoughts on web-based citation analysis," J. Inf. Sci., vol. 27, no. 1, pp. 1-7, 2001. 
[21] H. F. Moed, R. E. De Bruin, and T. N. Van Leeuwen, "New bibliometric tools for the assessment of national research performance: Database description, overview of indicators and first applications," Scientometrics, vol. 33, no. 3, pp. 381-422, 1995.

[22] A. L. Palmer, A. Sesé, and J. J. Montano, "Tourism and statistics. Bibliometric study 1998-2002," Annals of Tourism Research, vol. 32, no. 1. pp. $167-178,2005$.

[23] W. Glänzel, "The need for standards in bibliometric research and technology," Scientometrics, vol. 35, no. 2, pp. 167-176, 1996.

[24] V. Durieux and P. A. Gevenois, "Bibliometric indicators: quality measurements of scientific publication.," Radiology, vol. 255, no. 2, pp. 342-51, 2010.

[25] R. A. Benavent, J. C. V Zurian, M. C. Gomez, R. S. Melendez, and C. N. Molina, "Impact factor of the Spanish medical journals," Med. Clin. (Barc)., vol. 123, p. 697-701 ST-Impact factor of the Spanish medical, 2004.

[26] K. Sangwal, "Citation and impact factor distributions of scientific journals published in individual countries," J. Informetr., vol. 7, no. 2, pp. 487-504, 2013.

[27] K. Sangwal, "Some citation-related characteristics of scientific journals published in individual countries," Scientometrics, vol. 97, no. 3 , pp. 719-741, 2013

[28] E. GARFIELD, "From Citation Indexes to Informetrics: Is the Tail Now Wagging the Dog ?," Libri, vol. 48, no. 2, 1998.

[29] E. J. T. Manganote, M. S. Araujo, and P. A. Schulz, "Visualization of ranking data: Geographical signatures in international collaboration, leadership and research impact," J. Informetr., vol. 8, no. 3, pp. 642-649, 2014.

[30] Y. Dong, R. A. Johnson, Y. Yang, and N. V. Chawla, "Collaboration Signatures Reveal Scientific Impact," in Proceedings of the 2015 IEEE/ACM International Conference on Advances in Social Networks Analysis and Mining 2015 - ASONAM '15, 2015, pp. 480487.

[31] Z. Chinchilla-Rodríguez, B. Vargas-Quesada, Y. Hassan-Montero, A. González-Molina, and F. Moya-Anegón, "New approach to the visualization of international scientific collaboration,” Inf. Vis., vol. 9, no. 4, pp. 277-287, 2009.

[32] J. Lintott, "Evaluating the 'Hirsch hypothesis': A comment," Ecological Economics, vol. 52, no. 1. pp. 1-3, 2005.

[33] E. Csajbók, A. Berhidi, L. Vasas, and A. Schubert, "Hirsch-index for countries based on Essential Science Indicators data," Scientometrics, vol. 73, no. 1, pp. 91-117, 2007.

[34] M. Schreiber, "A case study of the Hirsch index for 26 non-prominent physicists," Ann. der Phys., vol. 16, no. 9, pp. 640-652, 2007.

[35] T. Gracza and I. Somoskövi, "Impact factor and/or Hirsch index?," Orv. Hetil., vol. 148, no. 18, pp. 849-852, 2007.

[36] L. Egghe, "Theory and practise of the g-index," Scientometrics, vol. 69, no. 1, pp. 131-152, 2006.

[37] C. T. Zhang, "The e-Index, Complementing the h-Index for Excess Citations," PLoS One, vol. 4, no. 5, 2009.

[38] A. Sidiropoulos, "Generalized h -index for Disclosing Latent Facts in Citation Networks," Scientometrics, vol. 72, no. 2, pp. 1-34, 2007.

[39] B. H. Jin, L. M. Liang, R. Rousseau, and L. Egghe, "The R- and AR-indices: Complementing the h-index," Chinese Sci. Bull., vol. 52, no. 6, pp. 855-863, 2007.

[40] P. D. Batista, M. G. Campiteli, O. Kinouchi, and A. S. Martinez, "Is it possible to compare researchers with different scientific interests?," Scientometrics, vol. 68, no. 1. pp. 179-189, 2006.

\section{AUTHOR PROFILE}

Guillermo Valencia Ochoa born in Barranquilla, Colombia. Is a full-time professor at the Universidad del Atlántico. Received a degree in Mechanical Engineering from Universidad del Norte, located in Barranquilla, Colombia in 2005. Master in Mechanical Engineering from Universidad del Norte, Barranquilla, Colombia in 2008. Ph. D in Engineering from the Universidad Pontificia Bolivariana, Medellin, Colombia in 2014. He is an assistant professor of the Mechanical Engineering Program, Specialization in Energy Efficient Management and Master in Energy Management at Universidad del Atlántico.

David Andrés Lorduy Martínez born in Cartagena, Colombia on May 22, 1997. He is a student in mechanical engineering at Universidad del Atlántico. In his undergraduate thesis, is working on Model-based fault detection in the air path of gas engines at Universidad del Atlántico.

Erni Ramos Banda born in Cartagena, Colombia on May 22, 1997. He is a student in mechanical engineering at Universidad del Atlántico. In his undergraduate thesis, is working onthermodynamic modelling study of absorption refrigeration systems at Universidad del Atlántico. 